\title{
Leadership influence on the relationship between communication satisfaction and job satisfaction in computer-mediated communication environments
}

\author{
Ever Bedoya \\ Faculty of Business and Economics \\ University of Pécs, Hungary
}

\begin{abstract}
Keywords
Computer-mediated communication; leadership; job satisfaction; communication satisfaction, level 5 leadership.
\end{abstract}

\begin{abstract}
The growth of computer-mediated communication (CMC) has influenced the communication process channels and the possible effects of the interaction between job satisfaction, communication satisfaction, and leadership. The aim of the current research is to test how transactional, transformational, and level 5 leadership styles influence the relationship between communication satisfaction and job satisfaction in CMC environments. The sample included 103 participants from Colombian small and medium-sized enterprises (SMEs) in the tertiary sector. Cronbach's alpha coefficient, SPSS was used to determine the relationships between variables and test the moderating effects. Results show that $65.4 \%$ of organisational communication is performed via the Internet. Findings also demonstrate that level 5 leadership is the only style that influences the relationship. Results also indicate that the influence of level 5 leadership increases the relationship between communication satisfaction and job satisfaction.

Implications are particularly relevant during the current global COVID19 pandemic when people have been required to move to a virtual work environment. In this scenario, the findings are valuable for scholars and managers as contributions for literature, research, evaluation, decision-making, and policy creation that help to understand and improve communication satisfaction, job satisfaction, and leadership practices in CMC environments. Outcomes offer new insights in the literature about leadership styles on SMEs in CMC environments. Level 5 is a recent leadership approach which has not been widely studied by researchers and scholars. The moderating effect of level 5 in relation to transactional and transformational leadership styles is an important theoretical input for literature.
\end{abstract}

Corresponding author: Ever Bedoya

Email addresses for the corresponding author: bedoyaever@gmail.com

The first submission received: $2^{\text {nd }}$ January 2021

Revised submission received: $17^{\text {th }}$ February 2021

Accepted: $1^{\text {st }}$ April 2021

\section{Introduction}

The expansion of internet networks, together with the increase in the use of mobile communication devices and the rise in interactions through computed-mediated communication, has changed the way people share information. On this issue, Derks, D. and Bakker, A. (2010), agree that computer-mediated communication (CMC) has turned to be a common exercise in work life, and a preferred channel of communication by employees (Stevens, et al., 2000). Eurofound and the International Labour Office (2017) asserted that the new information and communications technologies (ICT) have changed people's lives and work environment dramatically in the 21 st century.

The incorporation of ICT technologies in organisations has increased over the last 50 years. The development of new applications has shown benefits that are evidenced in restructuring processes inside and outside the organisation, improvements in the quality of products, support for innovation, and improvement of salary quotas. It is also expected an increase in new technology developed by the industries, and the subsequent extensive offer of possibilities and solutions it may provide (Bresnahan and Yin, 2017). 
The growth in the supply and use of Internet-based applications have led organisations to identify what social networks to use according to their characteristics; for example, a study carried out in 317 organisations found that if the purpose is communication with their clients, organisations recourse to the use of an application. When Pursuing visualisation, virtualisation, or collaboration functions, they use multiple social media applications (Go and You, 2016). The use of different social network applications helps to enhance organisational purposes, allows leaders to understand their uses more clearly, and increases organisational benefits. As shown in a study carried out in 567 Malaysian organisations, firms benefit from the use of social networks in different ways: possible pressures for competitors, two-way communication with the public that could help to gain new customers quickly, positive impact on organisations that may cause a cost reduction, customer relation enhancement, and improvement of information accessibility (Tajudeen, et al., 2018).

In addition, when referring to accurate sense of communication, current research supports an increase in the study of internet-based communication and its relationship with organisations for different purposes and with different tools. After analysing 6678 tweets, a study conducted in profit and non-profit organisations found that dialogic organisational communication impacted the relationship with customers. It means that a direct communication among the organisation and the customer influences the customer's engagement (Wang and Yang, 2020).

On the other hand, new technology greatly affects the existing organisational environment and influences the networks of the communication process. Although the positive relationship between the manager's communication satisfaction and job satisfaction is statistically demonstrated, electronic communication has had a negative effect on employees (Stich, et al., 2017), (Stich, et al., 2018). Internetbased technology in organisations has become a technical resource to increase the likelihood of communication, but it may also be inconvenient due to an increase in workload and unexpected and continuous commands, as well as the ambiguity, inaccuracy, and irrelevancy of task instructions, together with a huge number of daily emails employees must reply (Robbins and Judge, 2019), making employees work even during their time off (Barley, et al., 2011).

Finally, the increasing use and effect of ICT on job satisfaction poses enormous challenges for modern leaders to effectively convey orders, suggestions, and ideas.

\section{Literature Review}

\subsection{Job satisfaction}

Finding a single definition of job satisfaction is not an easy task because of the taxonomic impact from different areas and literature approach. To a large degree, one of the causes of complexity responds to the fusion of positions from the multidisciplinary theoretical intervention about determinants affecting job satisfaction, as shown in the following studies, e.g. (Lakhani, 1989; Clark and Oswald, 1996). The situation widely displays the spectrum of significance that strengthens literature but hinders theoretical framework delimitations to obtain a precise definition of the phenomenon. Schaffer (1953) agrees that employee's job satisfaction or dissatisfaction in the work environment is related to the same psychological mechanisms that causes them within and outside work; therefore, job satisfaction is the possibility of individual's needs, that can be satisfied in the work environment, to be truly satisfied. He also contemplates dissatisfaction as a state of tension to reach those needs, or the perception about the degree of tension to use the opportunities to achieve that satisfaction. In other words, job satisfaction is the perception that work fulfils important values of work, or allows the fulfilment (Locke, 1976). Paul Spector agrees on the duality of the concepts of satisfaction and dissatisfaction for the understanding of the phenomenon. He explains job satisfaction as "the extent to which people like (satisfaction) or dislike (dissatisfaction) their jobs" (Spector, 1997).

\subsection{Leadership: From transactional and transformational to level 5 leadership}

Leadership is an individual or social process deliberately exercised by one person over others to perform organisational and relational activities in a group (Yukl, 2013). This influential act leads to real changes to echo a mutual aim (Rost, 1993). To understand the socio-political context, Burns managed to establish the basic conceptual differences between transactional and transformational leaderships (Burns, 1978). Bass interprets the transactional leadership no longer as an exchange of mutual benefits between 
the leader and the follower, but as a delimitation of awards and punishments to generate results from managerial tasks. He suggests that the function of the transactional leader is limited to making the followers perform tasks, preserving their performance, and seeking solutions to possible conflicts (Bass, 1985). He assumes that rewards and punishments are tightly related to the adequacy of the follower's performance; on the other hand, real transformational leaders manage to inject a dose of motivation to followers so that they reach goals beyond what they could have ever imagined, accompanying the process of empowering followers for satisfaction and commitment; thus, followers may overcome their individual needs and develop potential levels of leadership as well (Bass and Riggio, 2006; Bass and Avolio, 1990; Bass, 1990, 1985). Mixing motivating and managerial features, level 5 leadership emerged. The identification of characteristics of level 5 leaders resulted of a study conducted between 1996 and 2000 by a group of 220 researchers led by Collins, (2001). On a sample of 1435 companies from all fields of industry and of all sizes, for 30 years (1965 to 1995), researchers identified the most successful organisations that turned from being good companies to positioning as excellent and enduring in the market. Researchers applied mixed techniques to collect data that included interviews, analysis of internal reports and analysis of the company, analysis of financial indicators, information on executive turnover, and behaviour of the firms' actions.

The empirical findings showed some unique characteristics of an unknown style of leadership that they called level 5 leadership; subsequently, researchers established a 5-level hierarchical table. At the top level, they located leaders who were able to lead organisations to excellence and endure the excellence over time. Collins classifies leaders as ambitious. From this perspective, "ambitious" does not represent greed and selfishness, but an ambition that translates into a collective purpose for the common good of the organisation, an ambition that results from the blending of three main behaviours: fanatical discipline, empirical creativity, and productive paranoia (Collins and Hansen, 2011). For researchers, the key to level 5 leaders' success lies in an equation expressed by the duality of humility and will (Humility + Will $=$ level $5)$.

\subsection{Communication Satisfaction and disruption of computer-mediated communication}

For Redding (1978), employees perceive a positive or negative communication satisfaction when they are in contact with their leaders, customers, and colleagues in the entire working environment. He describes the communication satisfaction as a general degree of satisfaction related to the employee's perception over the whole communication atmosphere. Thayer (1968) argues that communication satisfaction emerges out of a successful communication fulfilment. Regarding work environment, Putti, Aryee, and Phua (1990), agree on suggesting that communication satisfaction is the "available information that fulfils the individual's requests for information pertaining to the task-role or for simply being about organisational activities". The idea is reinforced by Steele and Plenty (2015), who define employee communication satisfaction as communication that satisfactorily fulfils tasks and meets relational needs of employees at work. Downs and Hazen (1977) also state that communication satisfaction is a multidimensional construct related to job satisfaction; as a result, researchers claim that the communication satisfaction construct is composed of 7 dimensions, namely: satisfaction with communication climate, satisfaction with supervisors, satisfaction with organisational integration, satisfaction with media quality, satisfaction with informal horizontal communication, satisfaction with general organisational perspective, and satisfaction with communication with subordinates (Downs and Hazen, 1977).

The disruption of computer-mediated communication takes place through all kinds of electronic media that people use to exchange, individually or in groups, synchronous or asynchronous messages (Martins and Ferro, 2008). The use of Internet-based communication is considered a true and undeniable useful resource (Stanko and Sena, 2019), that may affect all industries and motivate researchers to focus on investigating the effects that computer mediated technology use, or disuse, have on communication satisfaction (Siljanovska, 2015; Lalic, et al., 2012).

Evidence of the relationship between leadership, communication satisfaction, and job satisfaction have resulted from different studies.

A study testing the moderation effect of Confucian work dynamism on the relationship between communication satisfaction and job satisfaction, conducted on 408 full time employees from 53 five-star 
hotels in Hainan both domestic and franchised international hotels, showed a significant relationship between communication satisfaction and job satisfaction. The moderating effect of Confucian work dynamism on the relationship was weak (Hua and Omar, 2016). A research to identify the factors influencing job satisfaction, carried out on 145 ICU nurses from 2 Korean hospitals, found a significant correlation between job satisfaction and communication satisfaction. The study also concluded the impact communication satisfaction had on job satisfaction for participants working at a surgery ICU and dissatisfaction on employees working with nursing (Park and Lee, 2018). One more study conducted at the healthcare sector on a sample of 303 intensive care nurses from three different hospitals in Belgium, aiming at understanding the relationship between communication and job satisfaction and the relationship with intention to leave, evidenced a moderate relationship between all dimensions of communication satisfaction and job satisfaction. It also demonstrated high levels of communication and job satisfaction (Vermeir, et al., 2018). A study, conducted on 334 Indian managers from public and private sectors, aiming at determining the relationship between generational category and job satisfaction and satisfaction with organisational communication, showed a positive relationship between communication and job satisfaction, as well as a moderating effect of the generational category on the relationship between organisational communication and job satisfaction (Mehra and Nickerson, 2019).

Regarding the communication and job satisfaction relationship on Internet-based work environments, teleworking is defined as the use of ICT tools, namely, smartphones, tablets, laptops, and desktop computers to perform any job outside the employer's premises (Eurofound and the International Labour Office, 2017, p. 7). Teleworking is performed by utilizing ICT tools out of the employer's place (Belzunegui-Eraso and Erro-Garces, 2020). In this line, teleworking is partialy performed on CMC. Smith, Patmos, and Pitts conducted a study on 384 full time American teleworkers, aiming at exploring how personality traits and communication channel satisfaction of e-mail, instant messaging, phone, and video communication could affect job satisfaction. Among the findings, researchers could find a strong correlation between job satisfaction and communication channel satisfaction for e-mail, instant messaging, phone, and video (Smith, et al., 2018).

Consequently, the following hypothesis is proposed:

H1. Communication satisfaction has a positive and significant relationship with Job Satisfaction in CMC environments

Studies have also tested the multivariable relationship between leadership, communication, and job satisfaction. A study conducted on 225 people from Turkish deposit banks showed that interactive leadership style and communication competency have a stronger relationship with job satisfaction (Çetin, et al., 2012). A study focused on gender side opportunities in organisations on 200 employees at Indonesian universities, aiming at understanding the relationship between leadership styles, communication skills, and employee satisfaction, revealed that either communication skills, or task and relationship-oriented leadership styles are especially influential in determining employees' satisfaction with communication relationships with leaders, and their satisfaction with work (Wikaningrum, et al., 2018). A research carried out on 826 non-managerial employees at an international airport from a Turkish Private Security Company in Turkey tested the mediation effect of transformational leadership and communication competence on job satisfaction by considering the mediating role of communication satisfaction. Findings showed that when analysing individually, communication satisfaction and transformational leadership demonstrated significant positive relationships with job satisfaction; also, the SEM model tested a partial mediation effect of transformational leadership on the relationship between communication satisfaction and job satisfaction (Ulutürk and Tayfun, 2019).

Nowadays, technological advances and its implementation demand new scenarios for researchers. The present study explores the influence of leadership styles as moderators on the relationship between communication satisfaction and job satisfaction in CMC environments. As the current study involves CMC and unexplored leadership styles with moderating effects in internet-based environments, no literature reviewed has been found; nevertheless, literature reviewed for the current study seems to support that leadership styles influence the relationship between communication satisfaction and job satisfaction. Then, the following hypotheses are proposed: 
H2. Transactional leadership influences the relationship between communication satisfaction and employees' job satisfaction in CMC environments.

H3. Transformational leadership influences the relationship between communication satisfaction and employees' job satisfaction in CMC environments.

H4. Level 5 leadership influences the relationship between communication satisfaction and employees' job satisfaction in CMC environments.

Consequently, a research question is drawn:

What moderation effects do transactional, transformational, and level 5 leadership have on the relationship between communication satisfaction and job satisfaction in CMC environments?

In conclusion, the research allows the construction of a joint relationship of the variables to test the central hypothesis and understand if some contemporary leadership styles influence the relationship between communication satisfaction and job satisfaction. It also demonstrates how the relationship occurs, and which leadership styles impact it.

\section{Research Methodology}

\subsection{Sample}

For the current study, the probability sampling technique was used, since it is a reliable technique to apply when highly precise information is required to understand a phenomenon (Malhotra, 2010, p. 359).

The selection of organisations was based on three basic characteristics:

- First, operating in the tertiary sector of the economy.

- Second, being small and medium-sized enterprises.

- Third, being in the same country.

After that, a proportional stratified sampling was designed to make sure divisions of the subgroups were accurate (Strata / Stratum) (Gay, et al., 2012, p. 133).

Each organisation represented a subgroup, subsequently, for each candidate to have an equal probability of selection to participate, the simple random sampling technique was utilized in every stratum. It guaranteed every participant to be selected independently from the other participants. It also guaranteed a reliable procedure of a proportional stratified sampling (Malhotra, 2010, p. 350); consequently, an equal representation in proportion for every stratum of the population was assured (Gay, et al., 2012, p. 133). The questionnaires were administered on 103 participants.

To select the participants and avoid self-selection bias, the author used alphabetical databases from the organisations. As the purpose of the study is to understand all the communication satisfaction environment, the researcher selected both leaders and followers as potential sampling candidates; finally, for each stratum, the software (CalculatorSoup, LLC, 2019) generated random numbers.

The questionnaires were later typed on Microsoft Excel and analysed on IBM SPSS Statistics 22.

\subsection{Questionnaires}

Two criteria were followed to select the questionnaires: accurate theoretical approach related to the purpose of the study and consistent reliability measures.

Together with reliability tests from previous research, all questionnaires were measured during the current study; therefore, 5 questionnaires were utilised. At the beginning a series of socio-demographic questions were asked to participants. The socio-demographic section included questions related to the use of CMC tools and average use at the organisations. Job Satisfaction Survey instrument (JSS) (1985) was administered to measure job satisfaction. The 36-item JSS has been widely administered (Mesarosova, 2016), (Ofei-Dodoo, et al., 2018; Alharbi, et al., 2016; Malik and Yukun, 2019), and translated into several languages (Spector, 2018). The items were measured on a 6-point Likert-type scale ranging from 1 (Disagree very much) to 5 (Agree very much). The questionnaire had an original internal consistency reliability of .91 . The current research tested a consistent Cronbach's Alpha coefficient of .87 (M=69.17; $\mathrm{SD}=12.09)$.

Communication satisfaction was measured by Communication Satisfaction Questionnaire developed by (Downs and Hazen, 1977). The instrument was designed on a Likert scale ranging from 1 (Very dissatisfied) to 7 (very satisfied). The original questionnaire consisted of 8 dimensions; however, as 
the dimension relationship with subordinates was directed to participants who had people in charge, just a few questions were answered; therefore, the dimension was eliminated. Items number 36, 37, 38, 39, and 40 were removed. The final questionnaire for the current research consisted of 7 dimensions and 35 questions. Authors' original coefficient of reliability resulted in .94. The reliability test for the current research was .98 $(\mathrm{M}=179.78 ; \mathrm{SD}=40.55)$.

For leadership, 2 questionnaires were administered.

MLQ 5X was used to measure transactional and transformational leadership styles, and L5LS instrument was administered to measure level 5 leadership.

45-item MLQ 5X has been widely used by researchers and scholars (Curtis, et al., 2017; Choi, et al., 2017; Yaghoubipoor, et al., 2013; Salter, et al., 2010; López-Zafra, et al., 2008). Previous research showed a reliability coefficient of .94 . The questionnaire was designed on a Likert scale ranging from 0 (Not at all) to 4 (Frequently, if not always).

For the current research, just transactional and transformational leadership styles were analysed; consequently, section passive/avoidant leadership styles, consisted of factors Management -by-Exception (Passive) (Item numbers 3, 12, 17, 20) and Laissez-faire (Item numbers 5, 7, 28, 33) and the section other outcomes consisted of factors extra effort (Item numbers 39, 42, 44), satisfaction (Item numbers 38, 41), and effective (Item numbers 37, 40, 43, 45) were eliminated. The final questionnaire included 28 items. The current general Cronbach's Alpha was .94 (M=81.93; DS=19.24).

Level 5 leadership was measured by the 2-dimension L5LS instrument. The questionnaire was designed on a scale from 1 (The characteristic does not describe this person at all) to 10 (The characteristic describes him/her exactly). The 10-item questionnaire was originally assessed by testing dimensions separately. The Cronbach's alpha equalled .83 for personal humility and .83 for professional (Reid, et al., 2014). For the current research, the coefficient of reliability resulted in $.94(\mathrm{M}=79.49$; $\mathrm{SD}=18.02)$. A reliability test was performed to the dimensions independently. Personal humility presented a Cronbach's Alpha of $.92(\mathrm{M}=38.33 ; \mathrm{SD}=10.49)$ and Professional Will tested a Cronbach's Alpha coefficient of $.91(\mathrm{M}$ $=41.16 ; \mathrm{SD}=8.52$ ).

For the translation of the questionnaires into Spanish, the forward-backward translation method was applied for all questionnaires. It is a method of translating scientific measurement questionnaires widely used (Guillemin, et al., 1993; Yu, et al., 2004; Tsang, et al., 2017). The JSS questionnaire had a Spanish version suggested by the authors of the instrument. Conrado Marion-Landais carried out the questionnaire translation (Spector, 2018). It was later contrasted with the Spanish draft.

\subsection{Procedure}

To test the hypotheses a Pearson coefficient correlation analysis was performed; subsequently, the size of the effect of the independent variable on the dependent variable was determined.

Figure 1. Model

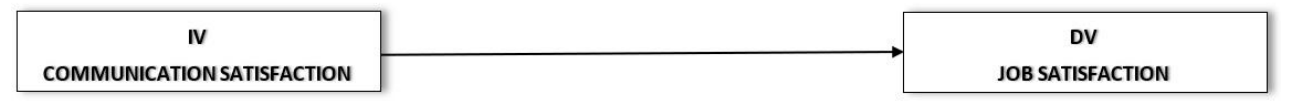

Source: Author

Once the relationship and the effect size of communication satisfaction with job satisfaction was found, it was tested if the effect of this relationship could be influenced by the three leadership styles. Pearson's correlation coefficient was used; subsequently, a moderated multiple regression model was used.

Figure 2. Moderation model

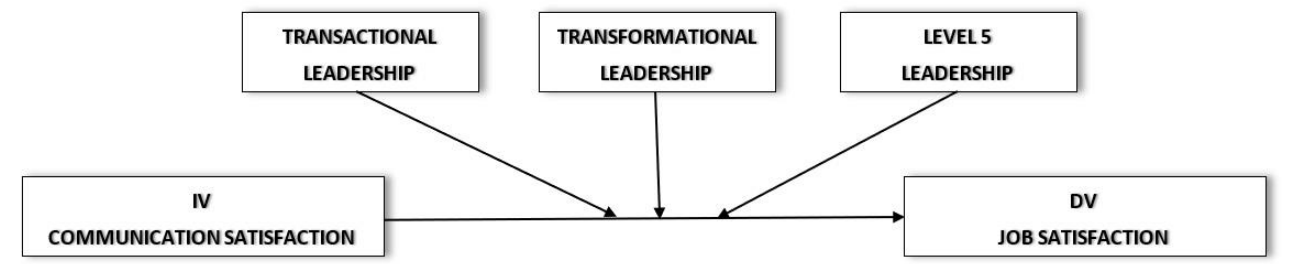

Source: Author 
The hypotheses were tested by using IBM SPSS Statistics 22; CODE: PROCESS version 3.4 (Hayes, 2018, 2019).

\section{Results}

\subsection{Sociodemographic data}

Regarding the gender, out of the participants who answered the questionnaires $(n=103), 46.6 \%$ of respondents $(n=48)$ were male and $53.4 \%(n=55)$ were female. Job tenure ranged from 1 to 38 years $(\mathrm{M}=6.83, \mathrm{SD}=7.0)$, and the time in charge of the same position ranged from 1 to 38 years $(\mathrm{M}=4.90$, $\mathrm{SD}=5.99) .49 .5 \%(\mathrm{n}=51)$ belong to the middle level at the chain of command in the organisation, $13.6(\mathrm{n}=14)$ to the top level, $10.7 \%(n=11)$ to the low level of command, and $26.2 \%(n=27)$ do not belong to any level of command.

To this study, employees responded that they spent an average of 5.4 hours a day using the internet to carry out their work activities. They also said that $65.4 \%$ of the organisational communication was done through the CMCs. The information allows us to infer that ICTs have been sufficiently used by organisations. The fact that $65.4 \%$ of Internet-based communication channels are used for organisational communication is relevant information to understand that Internet-based channels is the predominant communication way in these organisations.

\subsection{Hypothesis Tests}

H1. Communication satisfaction has a positive and significant relationship with Job Satisfaction in CMC environments

Table 1. Pearson's correlation coefficient

\begin{tabular}{lcc}
\hline Variable & & \\
\hline JS & - & - \\
CS & $.725^{* *}$ & - \\
\hline & ${ }^{* *}$. Correlation is significant at the 0.01 level (2-tailed). \\
& Source: Author
\end{tabular}

Pearson's correlation coefficient shows that there is a strong and significant relationship between the dependent variable job satisfaction and the independent variable communication satisfaction $r=.725$, $\mathrm{p}<0.01$. After that, the effect size and direction were determined.

Table 2. Coefficients H1

\begin{tabular}{llllll}
\hline & \multicolumn{4}{l}{ Unstandardized Coefficients } & \multicolumn{2}{c}{$\begin{array}{l}\text { Standardized } \\
\text { Coefficients }\end{array}$} & & \\
\cline { 2 - 4 } Model & B & Std. Error & Beta & S & Sig. \\
\hline 1 (Constant) & 68.121 & 8.141 & & 8.368 & .000 \\
CS & 16.178 & 1.546 & .721 & 10.461 & .000 \\
\hline
\end{tabular}

a. Dependent Variable: JOB SATISFACTION

Source: Author

Both the constant coefficient $(b=68.121, t=8.368)$ and the CS coefficient $(b=16.178, t=10.461)$ are significant at $p<.001$. The coefficient of the independent variable $(b=16.178, p<.001)$ indicates a positive relationship between job satisfaction and communication satisfaction. It means that the level of job satisfaction is expected to increase 16.178 units when communication satisfaction increases by one; as a result, the hypothesis is not rejected.

Subsequently, the moderation effect of leadership styles on the relationship between communication satisfaction and job satisfaction was tested.

Table 3. Pearson's correlation coefficient moderation $\mathrm{H}$

\begin{tabular}{llllll}
\hline Variable & 1 & 2 & 3 & 4 & 5 \\
\hline 1. JS & - & - & - & - & - \\
2. CS &, $721^{* *}$ & - & - & - & - \\
3. TRN & $.391^{* *}$ & $.596^{* *}$ & - & - & - \\
4. TRF & $.537^{* *}$ & $.690^{* *}$ & $.796^{* *}$ & - & - \\
5. L5LS & $.521^{* *}$ & $.725^{* *}$ & $.672^{* *}$ & $.794^{* *}$ & - \\
\hline
\end{tabular}

**. Correlation is significant at the 0.01 level (2-tailed).

Source: Author 
Pearson's correlation indicated a significant and strong relationship between the criterion variable job satisfaction and the predictor variable communication satisfaction $(r=.721, p<0.01)$. Between the job satisfaction dependent variable and the transactional leadership moderating variable, a significant and moderate relationship has been demonstrated $(\mathrm{r}=.391, \mathrm{p}<0.01)$. A significant and moderate correlation was also observed between the dependent variable job satisfaction and the moderator variable transformational leadership $(\mathrm{r}=.537, \mathrm{p}<0.01)$. Pearson's coefficient indicated a significant and moderate correlation between the criterion variable job satisfaction and the moderator variable level 5 leadership $(\mathrm{r}=$ $.521, \mathrm{p}<0.01)$.

H2. Transactional leadership influences the relationship between communication satisfaction and employees' job satisfaction in CMC environments.

Table 4. Model H2

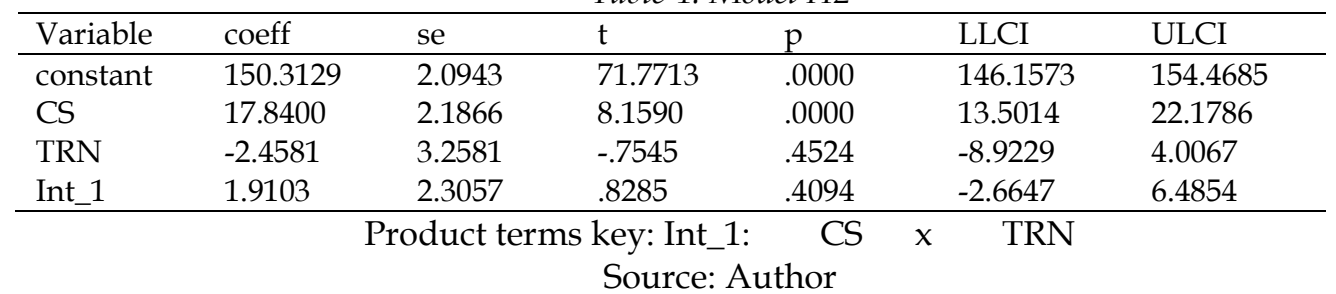

The interaction term coefficient was not significant $(b=1.91, t=0.829,95 \%$ CI. [-2.6647, 6.4854], $\mathrm{p}>$.05). It means that the relationship between job satisfaction and communication satisfaction was not moderated by transactional leadership; as a result, the hypothesis was rejected.

H3. Transformational leadership influences the relationship between communication satisfaction and employees' job satisfaction in CMC environments.

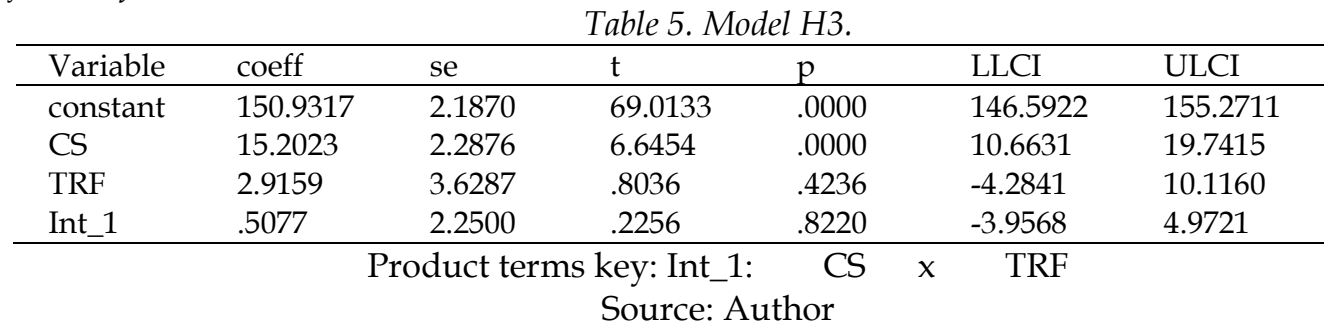

The interaction term coefficient was not significant $(b=0.508, t=0.226,95 \%$ CI. [-3.9568, 4.9721], $\mathrm{p}>$.05). It means that the relationship between job satisfaction and communication satisfaction was not moderated by transformational leadership; as a result, the hypothesis was rejected.

H4. Level 5 leadership influences the relationship between communication satisfaction and employees' job satisfaction in CMC environments.

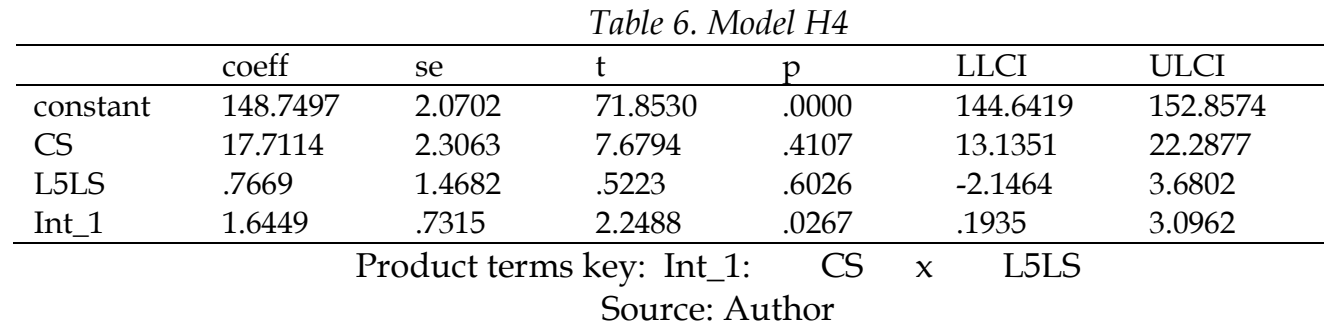

Test(s) of highest order unconditional interaction(s):

Table 7. Moderator

\begin{tabular}{|c|c|c|c|c|c|}
\hline & $\mathrm{R}^{2}$-chng & $\mathrm{F}$ & df1 & df2 & $p$ \\
\hline $\mathrm{X}^{*} \mathrm{~W}$ & .0233 & 5.0570 & 1.0000 & 99.0000 & .0267 \\
\hline & & edict: ( & $(\mathrm{X})$ & r: L5LS & \\
\hline
\end{tabular}

The relationship between the interaction term and the dependent variable (JS) was significant $(b=1.645, t=2.249,95 \%$ CI [.1935, 3.0962], $\mathrm{p}<.05)$; also, when the moderator term was added, the change in r2 was significant $(\mathrm{r} 2=023, \mathrm{p}<0.05)$. It indicates that the relationship between job satisfaction and communication satisfaction was moderated by level 5 leadership. 
As a result, the hypothesis was supported.

\subsection{Conditional effects}

Table 8. Descriptive Statistics H4

\begin{tabular}{llllll}
\hline & $\mathrm{N}$ & Minimum & Maximum & Mean & Std. Deviation \\
\hline CS & 103 & 1 & 7 & 5.14 & 1.158 \\
L5LS & 103 & 1 & 10 & 7.95 & 1.801 \\
\hline Valid & $\mathrm{N}$ & 103 & & & \\
(listwise) & & & & & \\
\hline
\end{tabular}

\begin{tabular}{lllllll}
\hline \multicolumn{7}{c}{$\begin{array}{c}\text { Source: Author } \\
\text { Table 9. Conditional effects }\end{array}$} \\
\hline L5LS & Effect & se & $\mathrm{t}$ & $\mathrm{p}$ & LLCI & ULCI \\
\hline-2.0845 & 14.2825 & 2.3764 & 6.0102 & .0000 & 9.5673 & 18.9978 \\
.5515 & 18.6184 & 2.4516 & 7.5945 & .0000 & 13.7540 & 23.4829 \\
1.7875 & 20.6515 & 2.9565 & 6.9851 & .0000 & 14.7851 & 26.5179 \\
\hline
\end{tabular}

Source: Author

The table 14 contains the values of three regressions.

Regression 1: Regression of the relationship between job satisfaction (DV) and communication satisfaction (IV) when the relationship is influenced by the low value $(-2.0845)$ of the level 5 leadership (Mod.).

Regression 2: Regression of the relationship between job satisfaction (DV) and communication satisfaction (IV) when the relationship is influenced by the moderate value (.5515) of level 5 leadership (Mod.).

Regression 3: Regression of the relationship between job satisfaction (DV) and communication satisfaction (IV) when the relationship is influenced by the high value (1.7875) of level 5 leadership (Mod.).

According to the data, the results are interpreted as follows:

Regression 1: When the influence of L5LS was low, there was a significant positive relationship between job satisfaction and communication satisfaction $b=14.283,95 \%$ CI $[9.5673,18.9978], t=6.010$, $\mathrm{p}<.001$.

Regression 2: When the influence of L5LS was moderate, there was a significant positive relationship between job satisfaction and communication satisfaction $b=18.618,95 \%$ CI [13.754, 23.483], $\mathrm{t}=7.595, \mathrm{p}<.001$.

Regression 3: When the influence of L5LS was high, there was a significant positive relationship between job satisfaction and communication satisfaction $b=20.652,95 \%$ CI $[14.785,26.518], t=6.985, p<.001$.

Data for visualizing the conditional effect of the focal predictor (table 15) were used to make the plot:

Graph 1. L5LS effect on JS-CS relationship

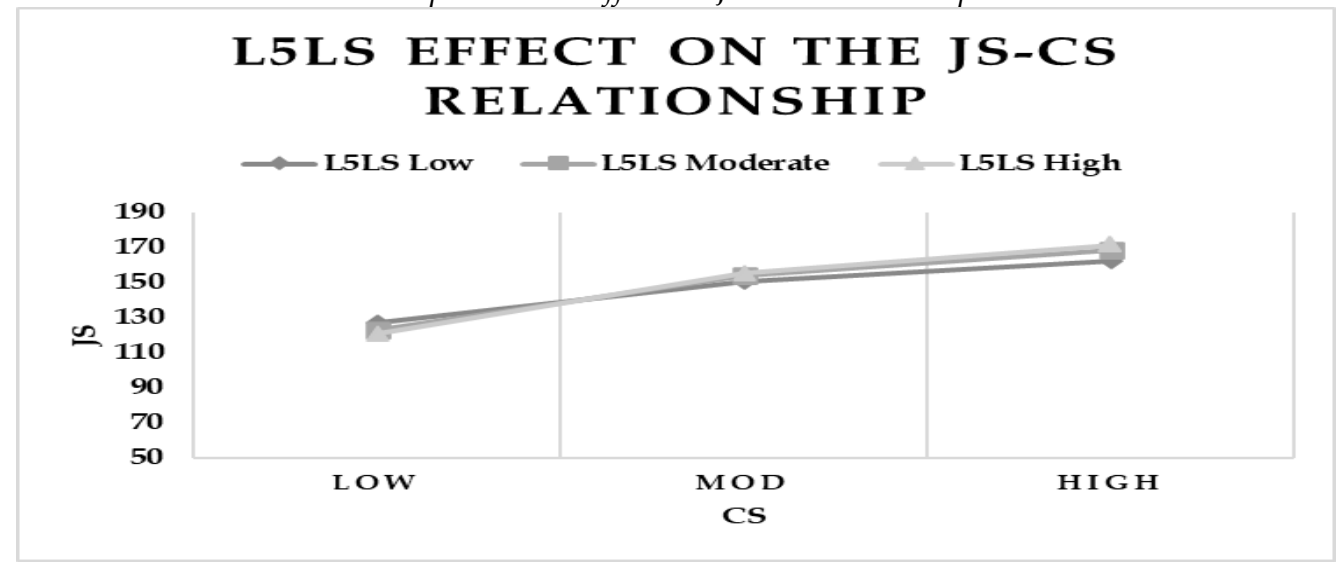

Source: Author

The plot shows the significant influence of level 5 leadership on the relationship between job satisfaction and communication satisfaction. 
The influence of level 5 leadership was significant at all values (low, moderate and high); nevertheless, when the value was high $(b=20.652,95 \%$ CI $[14.785,26.518], t=6.985, p<.001)$ the conditional effect of L5LS was higher than at low value $(b=14.283,95 \%$ CI $[9.5673,18.9978], t=6.010$, $\mathrm{p}<.001)$ or at moderate value $(\mathrm{b}=18.618,95 \% \mathrm{CI}[13.754,23.483], \mathrm{t}=7.595, \mathrm{p}<.001)$.

Therefore, the hypothesis H.c. was supported; level 5 leadership influences the relationship between communication satisfaction and employees' job satisfaction in CMC environments.

\subsection{Testing the research question}

What moderation effects do transactional, transformational, and level 5 leadership have on the relationship between communication satisfaction and job satisfaction in CMC environments?

It was observed that transactional leadership $(\mathrm{b}=1.91, \mathrm{t}=0.829,95 \% \mathrm{CI}$. [-2.6647, 6.4854], $\mathrm{p}>.05)$ and transformational leadership $(b=0.508, t=0.226,95 \%$ CI. [-3.9568, 4.9721], $\mathrm{p}>.05)$ had no moderating effect on the relationship between communication satisfaction and job satisfaction.

On the contrary, level 5 leadership had a significant and positive moderating effect on the relationship. The higher the value of the moderator $(b=20,652,95 \%$ CI $[14,785,26,518], t=6,985, p<.001)$, the greater the effect on the job satisfaction and communication satisfaction relationship.

\section{Discussion}

Results tested a positive relationship between communication satisfaction and job satisfaction. Results validate previous findings by (Hua and Omar, 2016; Park and Lee, 2018; Vermeir, et al., 2018; Mehra and Nickerson, 2019). The current study is also in line with previous results that have found communication satisfaction to have a moderate effect on job satisfaction (Vermeir et al., 2018). (Vermeir, et al., 2018). From the Internet-based work environments, results validate the findings presented by (Smith, et al., 2018) who found a strong relationship between communication and job satisfaction in CMC. Regarding the influence communication satisfaction has on job satisfaction, the results imply that the previous findings supporting the positive relationship between these two variables can be extended to SMEs using internet-based communication channels. It also allows to conclude that traditional organisational communication and communication based on the Internet have a similar impact when they are related to job satisfaction.

After finding the positive relationship between Internet-based communication and job satisfaction, Pearson's correlation coefficient analysis was used. The results showed a positive relationship between the criterion variable and the predictor variables; hence, the result validates previous findings (Çetin, et al., 2012; Wikaningrum, et al., 2018). This finding is conclusive, it demonstrates that when using both traditional communication and Internet-based communication, the relationships between communication satisfaction, job satisfaction, and the leadership styles are positive.

In the context of SMEs when leadership styles act as moderators of the relationship between job satisfaction and communication satisfaction, results demonstrated that transactional and transformational leadership styles have no effect on the relationship. It may occur because the current context of organisational communication is Internet-based, which could imply that SMEs should invest greater resources in employees and transactional and transformational leaders in training on modern high-tech resources.

On the contrary, regarding the results of the regression and the moderating effect, the findings tested that level 5 leader influences the relationship between communication satisfaction and employees' job satisfaction in CMC environments.

Consequently, an important insight in the literature is based in the fact that among the three leadership styles, level 5 is the only one affecting the relationship. It implies that the combination of professionalism and humility meets the modern demands to improve organisational tensions from the relationship between communication satisfaction and job satisfaction in internet-based communication environments.

Another unique finding proves that level 5 leadership impacts the relationship when the effect is low, medium, and high. The empirical exercise tested that when the effect is greater, the influence of leadership on the relationship between communication satisfaction and job satisfaction grows progressively higher than the low and moderate effects. It was also observed that the influence of level 5 
leadership increased the relationship between communication satisfaction and job satisfaction. It indicates that the better the perception employees have of level 5 leaders, the greater the impact employees have on the relationship. It means that potential tensions in the relationship between communication satisfaction and job satisfaction in a CMC environment decreases when level 5 leadership intervenes.

Finally, the outcomes allow to answer the research question by concluding that transactional and transformational leadership styles do not have influence on the relationship. Again, level 5 leadership is the only style that affects the relationship between communication satisfaction and job satisfaction in $\mathrm{CMC}$ environments. The fact that Level 5 leadership positively influences the relationship is a sign that staff members from SMEs respond to motivational elements other than rewards or empowerment. In this way, the result of the equation between Humility + Will is the answer for employees to feel more satisfied when modern communicational interactions occur in the work environment.

\section{Conclusions and managerial implication}

The results show that there is a positive relationship between communication satisfaction and job satisfaction in CMC environments. This implies that there are flaws in the way organisations are using social media tools to guarantee correct organisational communication. It is suggested that organisational communication experts and CEOs establish interaction mechanisms with members of the organisation to constantly assess the weaknesses of the communication process and the use of CMC channels.

Likewise, findings from this study show that level 5 is the only leadership style that influences the relationship between communication satisfaction and job satisfaction. Level 5 leadership style shows characteristics that are summarized in professional will and humility. It is recommended that SME managers identify level 5 leaders in organisations and allow them to participate actively in the modelling of organisational communication processes, listen to staff members, and accompany followers in task performance.

Finally, the current study shed new light on the progressive growth of CMC and its connection to organisational communication. As $\mathrm{CMC}$ has become a necessary medium of communication that uses emails and network tools, CEOs and communication experts should consider communication strategies together with training for all members of the organisation on the use and implementation of social networks tools to achieve a better scope of organisational communication to tell directions and give feedback.

\section{Direction for future research}

The study of level 5 leadership is still very recent in the leadership field. After observing the results and its influence on the relationship between communication satisfaction and job satisfaction in CMC environments, it is recommended to perform a multidimensional study to analyse authority characteristics of level 5 leaders and the relationships they may have with the professional Will and Humility dimensions. It is also recommended to carry out a study involving organisations worldwide to compare the results with those obtained in this research.

\section{Limitations}

Regarding the job satisfaction questionnaire, the facet operation procedure had a low Cronbach's alpha coefficient $(.460)$, as the design of the questionnaire suggests scoring the overall facets, it was followed the questionnaire constructor's recommendation to keep it.

Regarding the conceptual argument exposed by Collins (2001), level 5 leaders lead the firms from good to great and can be found in highly performing organisations. The current study was conducted in SMEs in Colombia, so it can be a limitation. It is also important to underscore that when referring to SMEs, the categorisation of a successful SME needs to be redefined, since in emerging economy environments the success of SMEs should not always be observed in terms of financial growing, but in the way they sufficiently struggle to compete and create jobs.

As the study was carried out in Colombia, cultural differences may affect the replication of the study in European countries, then it is a suggestion to analyse the local context before.

The study was conducted on SEMs from the service sector, applications in other sectors or enterprise size may generate different results. 


\section{References}

Alharbi, J., Wilson, R., Woods, C. \& Usher, K. (2016). The factors influencing burnout and job satisfaction among critical care nurses: a study of Saudi critical care nurses. Journal of Nursing Management, September, 24(6), pp. 708-17.

Barley, S. R., Meyerson, D. E. \& Grodal, S. (2011). E-mail as a Source and Symbol of Stress. Organisation Science, JulyAugust, 22(4), p. 887-906.

Bass, B. M. (1985). Leadership and performance beyond expectations. New York: The Free Press.

Bass, B. M. (1990). From transactional to transformational leadership: Learning to share the vision. Organisational Dynamics, 18(3), pp. 19-31.

Bass, B. M. \& Avolio, B. J. (1990). Developing Transformational Leadership: 1992 and Beyond. Journal of European Industrial Training, 14(5), pp. 21-27.

Bass, B. M. \& Riggio, R. (2006). Transformational leadership. 2 ed. Mahwah: Lawrence Erlbaum Associates, Inc.

Belzunegui-Eraso, A. \& Erro-Garces, A. (2020). Teleworking in the Context of the Covid-19 Crisis. Sustainability, 12(9), pp. 1-18.

Bresnahan, T. \& Yin, P. L. (2017). Adoption of New Information and Communications Technologies in the Workplace Today. Innovation Policy and the Economy, 17(1), pp. 95-124.

Burns, J. M. (1978). Leadership. New York: Harper \& Row.

CalculatorSoup, LLC (2019). Random Number Generator. [Online] Available at:

https://www.calculatorsoup.com/privacy.php [Accessed 1209 2019].

Çetin, M., Karabay, M. E. \& Efe, M. N. (2012). The Effects of Leadership Styles and the Communication Competency of Bank Managers on the Employee's Job Satisfaction: The Case of Turkish Banks. Procedia - Social and Behavioral Sciences, Volume 58, p. 227-235.

Choi, S. B., Kim, K. \& Kang, S. W. (2017). Effects of transformational and shared leadership styles on employees' perception of team effectiveness. Social Behavior and Personality: An International Journal, 45(3), p. 377-386.

Clark, A. E. \& Oswald, A. J. (1996). Satisfaction and comparison income. Journal of Public Economics, 61(3), pp. 359-381.

Collins, J. (2001). Good to Great: Why Some Companies Make the Leap... and Others Don't. New York: HarperCollins Publishers Inc.

Collins, J. \& Hansen, M. (2011). Great by Choice: Uncertainty, Chaos, and Luck - Why Some Thrive Despite Them All. New York: HarperBusiness.

Curtis, G. J., King, G. \& Russ, A. (2017). Reexamining the Relationship Between Thinking Styles and Transformational Leadership: What Is the Contribution of Imagination and Emotionality? Journal of Leadership Studies, 11(2), pp. $8-21$.

Derks, D. \& Bakker, A. B. (2010). The Impact of E-mail Communication on Organisational Life. Cyberpsychology: Journal of Psychosocial Research on Cyberspace, 4(1).

Downs, C. \& Hazen, M. (1977). A Factor Analytic Study of Communication Satisfaction. The Journal of Business Communication, 14(3), pp. 63-73.

Eurofound and the International Labour Office (2017). Working anytime, anywhere: The effects on the world of work. Geneva: Publications Office of the European Union, Luxembourg, and the International Labour Office.

Gay, L., Mills, G. E. \& Airasian, P. (2012). Educational research: competencies for analysis and applications. 10 ed. Boston: Pearson Education, Inc.

Go, E. \& You, K. (2016). But Not All Social Media Are the Same: Analyzing Organizations' Social Media. Telematics and Informatics, 33(1), pp. 176-186.

Guillemin, F., Bombardier, C. \& D., B. (1993). Cross-cultural adaptation of health-related quality of life measures: literature review and proposed guidelines. Journal of Clinical Epidemiology, 46(2), pp. 1417-1432.

Hayes, A. F. (2018). Introduction to Mediation, Moderation, and Conditional Process Analysis, Second Edition: A RegressionBased Approach. 2 ed. New York (New York): Guilford Press.

Hayes, A. F. (2019). The PROCESS macro for SPSS, SAS, and R. [Online] Available at:

http://processmacro.org/index.html [Accessed 1512 2019].

Hua, W. \& Omar, B. (2016). Examining communication satisfaction, Confucian work dynamism and job satisfaction: A comparative study of international and domestic hotels in Hainan, China. The Journal of the South East Asia Research Centre for Communication and Humanities, 8(1), pp. 105-127.

Lakhani, H. A. (1989). The Determinants of Job Satisfaction: A Multidisciplinary, Multivariate Analysis of the US Army, Alexandria: United States Army Research Institute for the Behavioral and Social Sciences.

Locke, E. A. (1976). The nature and causes of job satisfaction. In: Handbook of industrial and organisational psychology. Chicago (Illinois): Rand McNally, pp. 1297-1343. 
López-Zafra, E., Garcia-Retamero, R. \& Landa, J. M. A. (2008). The role of transformational leadership, emotional intelligence, and group cohesiveness on leadership emergence. Journal of Leadership Studies, 2(3), pp. 37-49.

Malhotra, N. K. (2010). Marketing Research: An Applied Orientation. 6 ed. Upper Saddle River: Pearson Education, Inc.

Malik, S. \& Yukun, C. (2019). Measuring Moderating Effect of Power Distance Between Facets of Job Satisfaction and Overall Decision of Job Satisfaction. In: Y. Mughal \& S. Kamal, eds. Servant Leadership Styles and Strategic Decision Making. Chicago: IGI Global, pp. 218-248.

Mehra, P. \& Nickerson, C. (2019). Organisational communication and job satisfaction: what role do generational differences play? International Journal of Organisational Analysis, 27(3), pp. 524-547.

Mesarosova, M. (2016). Psychometric properties of a job satisfaction survey in Slovakia in helping professionals: Preliminary results. Global Journal of Psychology Research, 6(4), pp. 195-201.

Muchinsky, P. M. (1977). Organisational communication: Relationships to organisational climate and job satisfaction. Academy of Management Journal, 20(4), p. 592-607.

Ofei-Dodoo, S., Scripter, C. \& Kellerman, R. (2018). Job Satisfaction and Burnout Among Nonclinical Workers in a Medical Education Center. Fam Med, 50(4), pp. 223-227.

Park, E. J. \& Lee, Y. M. (2018). Effect of Professional Autonomy, Communication Satisfaction, and Resilience on the Job Satisfaction of Intensive Care Unit Nurses. Journal of Korean Critical Care Nursing, 11(2), pp. 63-74.

Putti, J. M., Aryee, S. \& Phua, J. (1990). Communication relationship satisfaction and organisational commitment Studies. Group \& Organisation Studies, 15(1), pp. 44-52.

Redding, W. C. (1978). Communication within the organisation. New York: Industrial Communication Council.

Reid, W., Bud West, G. R., Winston, B. \& Wood, J. (2014). An Instrument to Measure Level 5 Leadership. Journal of Leadership Studies, 8(1), pp. 17-32.

Robbins, S. P. \& Judge, T. A. (2019). Organisational behavior. 18 ed. Boston: Pearson Education, Inc.

Rost, J. C. (1993). Leadership for the twenty-first century. Westport: Praeger Publishers.

Salter, C. et al. (2010). Virtual communication, transformational leadership, and implicit leadership. Journal of Leadership Studies, 4(2), pp. 6-17.

Schaffer, R. H. (1953). Job satisfaction as related to need satisfaction in work. Psychological Monographs: General and Applied, 67(14), pp. 1-29.

Smith, S. A., Patmos, A. \& Pitts, M. J. (2018). Communication and Teleworking: A Study of Communication Channel Satisfaction, Personality, and Job Satisfaction for Teleworking Employees. International Journal of Business Communication, 55(1), p. 44-68.

Spector, P. E. (1997). Job satisfaction: Application, assessment, causes, and consequences. Thousand Oaks: Sage.

Spector, P. E. (2018). Job Satisfaction Survey, JSS Translations. [Online] Available at:

http://shell.cas.usf.edu/ pspector/scales/jsstranslate.html [Accessed 1304 2019].

Steele, G. \& Plenty, D. (2015). Supervisor-Subordinate Communication Competence and Job Communication Satisfaction. International Journal of Business Communication, 52(3), pp. 294-318.

Stevens, P. M., Williams, K. P. \& Michael, C. S. (2000). Organisational communication and information processes in an Internet-enabled environment. Psychology \& Marketing, July, 17(7), p. 607-632.

Stich, J.-F., Tarafdar, M. \& Cooper, C. L. (2018). Electronic communication in the workplace: boon or bane? Journal of Organisational Effectiveness: People and Performance, 5(1), pp. 98-106.

Stich, J.-F.et al. (2017). Workplace stress from actual and desired computer-mediated a multi-method study. New Technology, Work and Employment, 32(1), pp. 84-100.

Tajudeen, F. P., Jaafar, N. I. \& Ainin, S. (2018). Understanding the impact of social media usage among organisations. Information E Management, 55(3), pp. 308-321.

Thayer, L. (1968). Communication and communication systems in organisation, management, and interpersonal relations. Homewood: Irwin, Inc.

Tsang, S., Royse, C. \& Terkawi, A. (2017). Guidelines for developing, translating, and validating a questionnaire in perioperative and pain medicine. Saudi Journal of Anaesthesia, May 11(Suppl 1), pp. 80-89.

Ulutürk, B. \& Tayfun, R. (2019). The Roles of Transformational Leadership, Communication Competence and Communication Satisfaction on Employees' Job Satisfaction. Journal of Communication Theory E Research, 49(1), pp. $48-68$.

Vermeir, P. et al. (2018). Communication satisfaction and job satisfaction among critical care nurses and their impact on burnout and intention to leave: A questionnaire study. Intensive $\mathcal{E}$ critical care nursing: the official journal of the British Association of Critical Care Nurses, July, Volume 48, pp. 21-27.

Wang, Y. \& Yang, Y. (2020). Dialogic communication on social media: How organisations use Twitter to build dialogic relationships with their publics. Computer in human behavior, 104(106183).

Wheeless, V., Wheeless, L. \& Howard, R. (1983). An analysis of the contribution of participative decision making and communication with supervisor as predictors. Research in Higher Education, Volume 18, pp. 145-160. 
Wikaningrum, T., Udin, A. S. \& Yuniawan, A. (2018). The relationships among leadership styles, communication skills, and employee satisfaction: A study on equal employment opportunity in leadership. Journal of Business and Retail Management Research, 13(1), pp. 138-147.

Yaghoubipoor, A., Puay Tee, O. \& Musa Ahmed, E. (2013). Impact of the relationship between transformational and traditional leadership styles on Iran's automobile industry job satisfaction. World Review of Entrepreneurship Management and Sustainable Development, 9(1), pp. 14-24.

Yu, D. S. F., Lee, D. T. F. \& Woo, J. (2004). Issues and Challenges of Instrument Translation. Western Journal of Nursing Research, 26(3), pp. 307-320.

Yukl, G. (2013). Leadership in organisations. 8 ed. Upper Saddle River (New Jersey): Prentice-Hall. 